\title{
A EVOLUÇÃO DO PROJETO F-X EM F-X2: \\ A DISPUTA DE EMPRESAS TRANSNACIONAIS EM PROCEDIMENTO LICITATÓRIO PARA A VENDA DE CAÇAS SUPERSÔNICOS COM IRRESTRITA TRANSFERÊNCIA DE TECNOLOGIA PARA O BRASIL
}

\author{
THE EVOLUTION OF THE F-X PROJECT IN F-X2: \\ THE DISPUTE OF TRANSNATIONAL COMPANIES IN A BIDDING \\ PROCEDURE FOR THE SALE OF SUPERSONIC FIGHTERS WITH \\ UNRESTRICTED TRANSFER OF TECHNOLOGY FOR BRAZIL
}

Recebido: 25.07.2017

Aprovado: 21.10.2017

Roberto Vinícius Hartmann* Luís Alexandre Carta Winter ${ }^{* *}$

RESUMO: Utilizando-se o método histórico dedutivo, o presente artigo traz a ideia de que os investimentos a serem realizados para a promoção da defesa nacional caracterizam-se como políticas públicas que devem ser implementadas pelogoverno. Sob essa perspectiva é que teve início no ano de 2000 um Plano de Fortalecimento de Controle do Espaço Aéreo Brasileiro, dentro do qual havia o projeto denominado de F-X, que consistia na aquisição de caças para a Força Aérea Brasileira (FAB). Referido projeto, após idas e vindas, acabou sendo relançado com a titulação de F-X2, em que se destacava que para a aquisição de caças supersônicos, a empresa vencedora do procedimento licitatório deve fazer a transferência irrestrita de tecnologia. Além disso, é feita uma análise sobre as empresas transnacionais e como ocorre a sua atuação para além das fronteiras do Estado de origem, evidenciando-se a sua relação com o projeto F-X2. Portanto, há que se ressaltar a utilização do método dedutivo para a realização do presente estudo.

Palavras-chave: Políticas públicas. Projeto F-X. Projeto F-X2. Transferência de tecnologia. Empresa transnacional.

ABSTRACT: Through the historical deductive method, this article presents the idea that the investments to be made for the promotion of national defense are characterized as public policies that should be implemented by the government. From this perspective it

\footnotetext{
* Advogado trabalhista, Graduado em Direito pela Pontifícia Universidade Católica do Paraná (PUC-PR), PósGraduado em Direito e Processo do Trabalho pela Universidade Anhanguera-Uniderp e Rede de Ensino Luiz Flávio Gomes e Mestrando no Programa de Pós-Graduação (Mestrado em Direito Econômico e Desenvolvimento) pela Pontifícia Universidade Católica do Paraná (PUC-PR). E-mail: < roberto_hartmann6o4@hotmail.com >.

** Graduação em Direito pela Universidade Federal do Paraná (1984). Especialização em Filosofia da Educação pela Pontifícia Universidade Católica do Paraná (1988), Mestrado em Integração Latino - Americana pela Universidade Federal de Santa Maria (2001) e Doutorado em Integração da América Latina pelo USP/PROLAM (2008). Professor titular da Pontifícia Universidade Católica do Paraná na graduação e na pós lato sensu onde coordena a especialização em Direito, logística e negócios internacionais, e no strito sensu, no mestrado e doutorado. Advogado. Consultor jurídico. Coordenador do NEADI (www.neadi.com.br). Membro de Centro de Letras do Paraná e do Instituto de Advogados do Paraná. E-mail: < luiz.winter@pucpr.br >.
} 
is that began in 2000 a Plan of Brazilian Airspace Control Strengthening, within which was the project called F-X, which consisted of the acquisition of fighter aircraft to the Brazilian Air Force (FAB). This project, after going back and forth, eventually being rereleased with the titration F-X2, where stood out that for the purchase of supersonic fighters, the winner of the bidding procedure should the unrestricted transfer of technology. In addition, an analysis is made on transnational companies and how is its performance beyond the State's borders, demonstrating their relationship with the F-X2 project. Therefore, it is worth noting the use of the deductive method for the realization of this study.

Keywords: Public policies. Project F-X. Project F-X2. Transfer of technology. Transnational companies.

\section{INTRODUÇÃO}

Os Países, de modo geral, protegem seus territórios, contra ameaças externas. Essa proteção decorre de uma política de defesa, consistente em leis e medidas concretas, tais como fabrico e/ou aquisição de armamentos. O espaço aéreo, pode ser comprometido e violado. O Brasil, com seu imenso território terrestre e marítimo, tradicionalmente pacífico, não poderia se furtar a ignorar este fato. O problema são os enormes custos para fazer frente à essas necessidades. A modernização, novas tecnologias, terão que serem levadas em conta, sempre. Daí a preocupação do custo/benefício de saber, dentro disto, se realmente necessitamos de um caça supersônico, para fins de defesa, ele terá que ser brasileiro? Isto é, temos, realmente que possuir a tecnologia para tal?

O presente artigo portanto, parte, tendo-se por base uma metodologia histórico dedutiva, em analisar a necessidade que o Brasil têm de modernizar-se, em consonância com sua Política de Defesa Nacional, na compra de seu caça supersônico. Para tanto, trabalha-se, inicialmente, com uma abordagem da própria política de defesa nacional, no projeto F-X ao F-X2, das vantagens e desvantagens dos concorrentes, passando pelo papel das empresas transnacionais nesse cenário, para, ao fim ter a resposta.

\section{DA POLÍTICA DE DEFESA NACIONAL}

Os investimentos na área militar, e em especial no que tange ao poderio aéreo, se dá em razão de que o Brasil almeja colocar-se como Potência Regional a ser respeitada no cenário Global e, mais, para alguns experts, "não apenas como potência econômica e política no continente, mas também como uma força militar respeitável e proporcional a sua grandeza" (DIAS JUNIOR; PORTO, 2010, p. 65).

O Brasil não se pode menosprezar a importância das forças armadas manteremse bem equipadas, sendo inclusive essa uma preocupação apresentada na introdução à Política de Defesa Nacional:

Após um longo período sem que o Brasil participe de conflitos que afetem diretamente o território nacional, a percepção das ameaças está desvanecida 
para muitos brasileiros. Porém, é imprudente imaginar que um país com o potencial do Brasil não tenha disputas ou antagonismos ao buscar alcançar seus legítimos interesses. Um dos propósitos da Política de Defesa Nacional é conscientizar todos os segmentos da sociedade brasileira de que a defesa da Nação é um dever de todos os brasileiros. (BRASIL, 2005).

Portanto, ao se tratar de questões militares está se falando na garantia da defesa nacional, a qual compete a União promovê-la através de políticas públicas, de acordo com ao artigo 21, III da Constituição de 1988, sendo que a Defesa Nacional se constitui como o "conjunto de medidas e ações do Estado, com ênfase na expressão militar, para a defesa do território, da soberania e dos interesses nacionais contra ameaças preponderantemente externas, potenciais ou manifestas" (BRASIL, 2005).

Nesse viés, temos que o eixo normativo da defesa nacional é composto pela Política de Defesa Nacional (2005), a qual se apresenta como a essência da defesa nacional, constituindo o documento vinculante de maior hierarquia da defesa nacional (ALMEIDA, 2010, v. 16) e pela Estratégia Nacional de Defesa (2008), sendo um desdobramento essencial da Política de Defesa, voltado para a implementação de ações concretas no campo da defesa, chegando a representar verdadeira redefinição estrutural, em que destaca o objetivo de estreitamento das relações entre as forças armadas com a sociedade civil, com a universidade e a introdução do conceito de capacidades para o planejamento de longo prazo (ALMEIDA, 2010, v. 16).

Contudo, a Defesa Nacional normalmente foi relegada a segundo plano, em razão de alguns fatores: 1 - em razão de um passado recente vivido com o golpe militar de 1964 criou-se certa restrição com os militares; 2 - porque se tem a ideia de que não temos problemas militares em razão do longo período sem conflitos armados; 3 quando se fala em políticas públicas, a opção pela realização de determinada medida reflete necessariamente na abdicação de outra (o chamado trade-off) e num país em que vivemos com situações tão alarmantes de problemas sociais, estes sempre são postos na pasta prioritária; 4 - por fim, os investimentos na Defesa Nacional não se apresenta como uma pauta que garantirá a eleição de governantes (ALMEIDA, 2010, v. 16). Assim, para que seja possível superar essas adversidades para os investimentos na área militar, a política de defesa deve ser repensada, de modo que:

Ao dizer respeito à própria existência do país, a política de defesa deve ser tratada como política de Estado, acima das rivalidades partidárias e das trocas de comando no governo. As escolhas relativas à defesa nacional devem levar em conta os outros bens ou serviços públicos que deixarão de ser providos com vistas à sua implementação, sem esquecer as características específicas e o caráter essencial do "bem defesa". Essa evolução somente poderá ser obtida com o envolvimento das diferentes instâncias de gestão, pesquisa e transparência interessadas no assunto: um conjunto institucional de atores políticos, públicos e privados, muito mais amplo do que o restrito círculo das forças armadas. O esboço de qualquer estrutura de defesa em uma democracia, para que tenha legitimidade e conte com recursos, deve vir da aprovação da sociedade. (ALMEIDA, 2010). 
Portanto, muito embora o anseio das pessoas seja sempre pela imediatidade dos resultados, os planos para investimento nas forças armadas devem ser de longo prazo por meio de políticas de Estado que tragam efetividade no aparelhamento militar, além de que os procedimentos licitatórios para a aquisição dos bens públicos militares deve ser feita com a maior lisura possível, para que não se deixem dúvidas quanto ao cumprimento de todas as medidas legais.

\section{DO PROJETO F-X AO F-X2}

Tudo se inicia no ano de 200o, quando o presidente Fernando Henrique Cardoso anuncia o Plano de Fortalecimento de Controle do Espaço Aéreo Brasileiro, que com o objetivo de fazer a compra de "150 aviões, 4 helicópteros de grande porte e a modernização dos caças F-5 e AMX” (DIAS JUNIOR; PORTO, 2010, p. 66) com o intuito de fazer a modernização em todo o aparato de combate da Força Aérea Brasileira (FAB), já que naquele tempo havia um contingente de 754 aeronaves, sendo que apenas 354 destas estavam operando, já que as demais não podiam ser utilizadas, seja por falta de peças de reposição ou porque não era disponibilizado orçamento suficiente para abastecimento e funcionamento (DIAS JUNIOR; PORTO, 2010, p. 66).

Ainda, dentro do referido Plano de Fortalecimento Aéreo estava incluído o chamado Projeto F-X, que consistia da compra de 12 a 24 caças novos, já que os antigos F103 Mirage III BR estavam completamente defasados, uma vez que "somente 5 ou 6 ainda voavam, porém virariam sucata, tal como os outros, em 2005, ano em que completaram 30 anos de utilização" (DIAS JUNIOR; PORTO, 2010, p. 66). Diante dessa situação, era pujante a necessidade do reaparelhamento dos caças da Força Aérea Brasileira, sob pena de ficarmos sem qualquer aeronave deste porte apta à utilização.

Assim, em agosto de 2001, deu-se início ao procedimento licitatório para a aquisição dos novos caças, o que se deu através da modalidade convite, de acordo com os preceitos do artigo 22, III da Lei no. 8.666/93, de modo que foram enviados convites para empresas estrangeiras especificando que para a aquisição dos caças supersônicos o governo havia disponibilizado do montante de aproximadamente 1,75 bilhões de reais à época (DIAS JUNIOR; PORTO, 2010, p. 66). A partir do que foi entabulado pelo artigo 22, § 3º. da Lei no. 8.666/93 se extrai que:

O convite é o procedimento mais simplificado dentre as modalidades comuns de licitação. Prevê-se a faculdade de a Administração escolher potenciais interessados em participar da licitação. Esses convidados não necessitam estar cadastrados previamente. Mas se admite a participação de quaisquer outros interessados “(...) que manifestarem seu interesse com antecedência de até 24 (vinte e quatro) horas da apresentação das propostas", desde que cadastrados. (JUSTEN FILHO, 2014, p. 353).

Assim, o procedimento licitatório na modalidade convite é aquele que pode ser aplicado para a compra de bens públicos, sendo que garante uma certa discricionariedade para a Administração escolher os candidatos, contudo devem ser observados critérios objetivos para a seleção dos concorrentes, sob pena de violação dos princípios da isonomia 
e igualdade, de modo que se "[...] a administração escolher determinados licitantes ou excluir outros por preferências meramente subjetivas, estará caracterizado desvio de finalidade e o ato terá de ser invalidado" (JUSTEN FILHO, 2014, p. 353), sendo está uma das razões pela qual a legislação já previu um mínimo de 03 interessados para se enviar os convites, assegurando desta forma uma maior observância de critérios equânimes.

Contudo, naquele período muitos políticos queriam que se abrisse mão do procedimento licitatória para privilegiar uma compra direta com a Empresa Brasileira de Aeronáutica S.A. (EMBRAER) (DIAS JUNIOR; PORTO, 2010, p. 66), pois quando se privilegia a compra de empresa brasileira exclusiva de fabricação ou no intuito de se manter uma padronização dos equipamentos utilizados pelas Forças Armadas, a lei de licitações nos incisos XIX e XXVIII do artigo 24 dariam sustentáculo para a dispensa da licitação. Veja-se, pois:

Art. 24. É dispensável a licitação: [...] XIX - para as compras de material de uso pelas Forças Armadas, com exceção de materiais de uso pessoal eadministrativo, quando houver necessidade de manter a padronização requerida pela estrutura de apoio logístico dos meios navais, aéreos e terrestres, mediante parecer de comissão instituída por decreto; [...] XXVIII - para o fornecimento de bens e serviços, produzidos ou prestados no País, que envolvam, cumulativamente, alta complexidade tecnológica e defesa nacional, mediante parecer de comissão especialmente designada pela autoridade máxima do órgão. (BRASIL, 1993).

No que tange o mencionado inciso XIX do artigo 24, Marçal Justen Filho destaca que "[...] verificando-se a necessidade de padronização e constatando-se existir um único fornecedor para determinados bens, aplicar-se-ia o art. 25, I, da Lei no․ 8.666/1993. Atingir-se-ia o mesmo resultado através da conjunção do art. 15, I com o art. 25, I" (JUSTEN FILHO, 2014, p. 453). Além disso, importante trazer à baila os ensinamentos do referido autor no que pertine o inciso XXVIII do artigo 24 da Lei nº. 8.666/93, senão vejamos:

\begin{abstract}
O dispositivo disciplina casos que pressupõem a presença de dois requisitos de distinta natureza. Trata-se da elevada complexidade tecnológica dos bens ou serviços e a vinculação com a defesa nacional. A configuração de tais casos vaise tornando comum em vista do progresso tecnológico e de sua aplicação para a defesa dos interesses coletivos [...] É relevante a expressão "nacional" porque impõe uma dimensão supraindividual e transcendente para os interesses serem defendidos. (JUSTEN FILHO, 2014, p. 473/474).
\end{abstract}

Mas, ainda que houvesse a previsão legal para a dispensa da licitação, o procedimento foi mantido e permaneceram na concorrência às seguintes aeronaves: 1 - Miragem 2000-5 Mk2 da empresa Dassault (França) que estava em parceria com a Empresa Brasileira de Aeronáutica S.A. (EMBRAER); 2 - F-16C Falcon da fabricante Lockheed Martin (Estados Unidos da América); 3 - Sukhoi-35 da Rosoboronexport (Rússia) e; 4 - JAS-39 Gripen C da Saab (Suécia) (DIAS JUNIOR; PORTO, 2010, p. 66).

Com o decurso do tempo a escolha do caça supersônico que seria adquirido pelo Brasil passou a sofrer diversos adiamentos, seja por motivos de análise técnica mais aprofundada ou pela mudança no governo que ocorreria em 2002 com a eleição de Luiz 
Inácio Lula da Silva. Após a eleição, de imediato houve novo adiamento, uma vez que o então presidente realizou o denominado trade-off como acima exposto, e optou por privilegiar o programa Fome Zero em detrimento da aquisição de aeronaves, o que retoma a discussão de que a maioria das pessoas não vê a política pública de reaparelhamento da Força Aérea Brasileira (FAB) como uma prioridade na pauta do governo e ciente disso, o presidente fez a sua opção pela política pública que visava a carência social do país (DIAS JUNIOR; PORTO, 2010, p. 67).

Muito embora o procedimento licitatório tenha sido reaberto em outubro de 2003 com a possibilidade de alteração das propostas anteriormente apresentadas pelas empresas participantes (DIAS JUNIOR; PORTO, 2010, p. 67), o projeto voltou a sofrer constantes adiamentos até que no início de 2005 a Força Aérea Brasileira (FAB), em comunicado oficial, pôs fim ao projeto F-X (DIAS JUNIOR; PORTO, 2010, p. 68). $\mathrm{O}$ grande problema é que naquele ano os caças F-103 Mirage III BR que restavam em funcionamento deveriam ser aposentados, não restando outra opção para a FAB senão um plano alternativo, que consistia na aquisição de aeronaves que já estivessem em uso em outros países, mas que ainda estivessem em boas condições, sendo então que no mês de junho de 2005 o "Brasil fechou a compra com a França. 12 caças Mirage 2000-5 em bom estado de conservação por US\$ 57 milhões" (DIAS JUNIOR; PORTO, 2010, p. 68).

A partir desse momento, em que se tem uma solução momentânea para a defasagem de aeronaves das Forças Armadas, o governo brasileiro começa a desenvolver um planejamento para um reaparelhamento condizente e necessário de caças de combate militar e, é sob essa perspectiva que surge o projeto F-X2, que consiste em "Abrir um novo programa para aquisição de caças de quarta geração, mais modernos do que os da disputa anterior [...] teve como principal bandeira a transferência de tecnologia" (DIAS JUNIOR; PORTO, 2010, p. 68), além de ser estabelecido no procedimento licitatório o direito de fabricação do caça vencedor pelo Brasil, bem como a exportação para o mercado sulamericano. Todos esses fatores que foram cumulados na elaboração desse projeto mais audacioso, demonstram um verdadeiro interesse do país da sair da condição de mero comprador de armamento de combate militar para um status de fabricante e exportador de aviões com alta tecnologia (DIAS JUNIOR; PORTO, 2010, p. 69), senão vejamos:

\footnotetext{
Mais do que obter uma máquina de guerra, o programa FX-2 foca na autonomia para a fabricação de um avião moderno e que deve levar a reboque a renovação e melhoria de diversos setores da economia e da pesquisa nacional. O conceito chave que definirá a escolha desses aviões de caça é a chamada TT, sigla para transferência de tecnologia. O processo de TT é garantia de que o investimento feito para um cenário hipotético de guerra se transforme em um projeto de modernização na área de pesquisa e desenvolvimento, paralelamente à capacitação de diversos setores industriais do país que poderão, em alguns anos, voar alto no cenário global. (BARBOSA, p. 42).
}

Preenchidos os requisitos exigidos no procedimento licitatório, mantiveramse no na disputa os seguintes caças supersônicos: 1 - Rafale F3 da empresa Dassault (França); 2 - JAS 39 Gripen New Generation da fabricante Saab (Suécia) e; 3 - F-18 E/F Super Hornet da companhia Boeing (Estados Unidos da América). 
Em setembro de 2009 se desenhou um cenário que parecia completamente favorável à empresa francesa na conquista da disputa, pois o então presidente Luiz Inácio Lula da Silva emitiu uma nota oficial de que seriam adquiridos os modelos Rafale F3, se cumpridas todas as condições da licitação e, em especial, a transferência irrestrita de tecnologia, já que se tratava de decisão de cunho eminentemente politico-estratégica do Presidente. Muito embora tenha ocorrido este comunicado de forma precipitada, foi assegurado que toda a análise técnica das propostas seria devidamente avaliada pela Força Aérea Brasileira (FAB), a qual ficou insatisfeita ao ser pega de surpresa com a nota oficial da Presidência da República. Ademais disso, tal situação causou ainda maior desconforto quando da emissão de um relatório final pela FAB colocou o Rafale F3 em último colocado, perdendo para o F-18 Super Hornet (2º. lugar) e para o JAS-39 Gripen NG ( $1^{\circ}$. lugar), sendo que este apresentaria vantagens sobre os demais no que tangem os seus custos, tanto no valor de cada unidade quanto no dispêndio financeiro para mantêlos em pleno funcionamento (FOLHA DE S. PAULO, 2010). Inclusive, ainda em 2009 a Empresa Brasileira de Aeronáutica S.A. (EMBRAER) já havia se posicionado de forma favorável à aquisição dos caças suecos, pois o consideravam a melhor escolha no quesito transferência de tecnologia para o Brasil (SILVEIRA, 2009).

Após tantas discussões, análises, adiamentos e mais de 13 anos transcorridos, finalmente no dia 18 de dezembro de 2013 o Projeto F-X2 tem a sua decisão final tomada pela Presidente Dilma Roussef dando a vitória para a empresa sueca Saab e o caça JAS 39 Gripen New Generation, sendo que para o resultado foram levados em consideração a transferência irrestrita de tecnologia, o desempenho e os custos da aeronave, bem como as contrapartidas comerciais asseguradas pela fabricante. $O$ resultado final da licitação consiste em um plano para a aquisição “[... 36 aeronaves, embora exista a possibilidade de o Brasil adquirir até 120 aviões em contratos de longo prazo posteriores. Os investimentos atuais são da ordem de US\$ 4,5 bilhões [...]" (UBIRATAN, 2014), sendo que além da compra das aeronaves, pactuou-se a aquisição do "[...] suporte logístico e compra de armamentos necessários à operação dos caças” (FORÇA AÉREA BRASILEIRA, 2016a), bem como que aproximadamente " $40 \%$ do caça Gripen e até $80 \%$ da sua estrutura serão feitos no Brasil” (SILVEIRA, 2013). O que se tem previsto é que o primeiro caça seja entregue ao Brasil em 2019 e o último até 2024 (FORÇA AÉREA BRASILEIRA, 2016a).

Destaca-se que a aquisição dos caças suecos trouxe uma repercussão muito favorável para o aprimoramento de algumas empresas, em especial a EMBRAER e a Akaer, sendo que a primeira "[...] coordenará todas as atividades de desenvolvimento e produção no Brasil, em nome da Saab, e, além de uma grande parcela de trabalho neste projeto, a Empresa também participará do desenvolvimento de sistemas, da integração, testes em voo, montagem final e entregas. [...] Além disso, a Embraer e a Saab serão responsáveis pelo desenvolvimento completo da versão biposto do Gripen NG [...]” (EMBRAER, 2014) e a segunda ficou incumbida de fazer o projeto de toda a fuselagem central, a traseira e as asas do JAS 39 Gripen NG (SILVEIRA, 2013).

Diante de todo o tempo percorrido para que se chegasse a uma decisão final ao projeto F-X2 houve questionamento quanto a honradez do procedimento licitatório 
ao passo que havia sido desencadeado um inquérito civil para a apuração de eventuais irregularidades. Contudo, no dia 25 de agosto de 2015 o referido inquérito foi arquivado pela Procuradoria da República, a qual ressaltou que:

[...] durante a investigação não foram encontrados elementos que justifiquem a continuidade da mesma e o ajuizamento de ações judiciais relacionadas ao assunto em questão. Com isso, ficou claro que o processo de aquisição foi conduzido com lisura. [...] Por fim, o Comando da Aeronáutica enfatiza que o processo em questão envolveu mais de 30.000 páginas de estudos técnicos e sempre foi pautado na valorização dos aspectos comerciais, técnicos, operacionais, logísticos, industriais, compensação comercial (offset) e transferência de tecnologia. (FARCIC, 2015).

Não houve nenhuma irregularidade na licitação, sendo que foram cumpridos todos os preceitos legais e o procedimento foi conduzido com total integridade, a medida que foram observados os princípios jurídicos da isonomia, legalidade, impessoalidade, moralidade, igualdade, publicidade e da probidade administrativa, entabulados no artigo 3ㅜ. da Lei no .8 .666 /93 (BRASIL, 1993).

Desta forma, a aquisição dos caças supersônicos pelo governo brasileiro, além de trazer um reaparelhamento moderno para as Forças Armadas Brasileira (FAB), garantiu enorme avanço tecnológico através da transferência de tecnologia irrestrita, sendo que:

Até 2022, mais de 350 brasileiros vão trabalhar com o projeto Gripen na Suécia. Os profissionais vão atuar no desenvolvimento da aeronave, gerenciamento de projetos, desenvolvimento de simulares e certificação, dentre outras atividades. Segundo o Departamento de Produtos de Defesa do Ministério da Defesa, o projeto de aquisição dos caças Gripen NG vai gerar 9,1 bilhões de dólares em compensações para o Brasil. Isto atende à Estratégia Nacional de Defesa, que prevê capacitar a indústria nacional. As compensações beneficiam as empresas brasileiras Embraer, Akaer, SBTA, Atech, AEL, Mectron e Inbra, além do Departamento de Ciência e Tecnologia Aeroespacial (DCTA), órgão da Aeronáutica em São José dos Campos (SP) (FORÇA AÉREA BRASILEIRA, 2016a).

Destaca-se por fim, que o JAS 39 Gripen E New Generation já teve encerrada a fase de desenvolvimento com a sua apresentação no dia 18 de maio de 2016 na sede da fabricante na cidade de Linköping (Suécia), sendo que a partir de agora será iniciada a fase de ensaios de voo (FORÇA AÉREA BRASILEIRA, 2016b), podendo, eventualmente, haver alguns atrasos, em decorrência da crise econômica que atinge ao Brasil.

\section{VANTAGENS E DESVANTAGENS DOS CONCORRENTES}

Dentre as muitas questões envolvendo as três aeronaves que foram finalistas na disputa no Projeto F-X2, importante trazer a baila alguns dos pontos positivos e negativos que foram relevantes na decisão final que deu a vitória para o caça sueco.

Nesse viés, o vencedor apresentava as seguintes vantagens: 1 - transferência de tecnologia: uma vez que o caça ainda era um protótipo, o Brasil teria condições de participar do desenvolvimento do mesmo (BARBOSA, p. 45); 2 - Em um dos relatórios da Força Aérea Brasileira (FAB) ficou evidenciada que o custo global (por unidade e de 
manutenção) do referido caça era muito inferior ao dos concorrentes, sendo esse um fator de grande relevância, já que "com menos gastos em manutenção, maiores são as chances de se manter bem armados estes caças, com mísseis e bombas de última geração” (DIAS JUNIOR; PORTO, 2010, p. 69); 3 - é o caça mais leve dentre os finalistas, o que garante um peso ideal para os porta-aviões em funcionamento no Brasil. Contudo, o referido avião apresenta as seguintes desvantagens: 1 - peças americanas: uma das grandes preocupações se dava em razão de que alguns equipamentos da aeronave continham peças oriundas dos Estados Unidos da América, o qual poderia impor entraves para a transferência de tecnologia (DIAS JUNIOR; PORTO, 2010, p. 69); 2 - panorama político: dentre os finalistas, a Suécia é o país que apresentava a menor relevância política no contexto global (DIAS JUNIOR; PORTO, 2010, p. 69); 3 - o último ponto negativo vai de encontro com o primeiro ponto positivo, ou seja, o fato de que o Gripen NG ainda estar em desenvolvimento, uma vez que corria-se o risco de "sair mais caro do que o esperado ou mesmo não se concretizar" (BARBOSA, p. 45).

Já o avião norte-americano F-18 E/F Super Hornet tinha as seguintes vantagens: 1 já era testado e aprovado em combate; 2 - a adaptação ao caça seria mais favorável, já que a Força Aérea Brasileira (FAB) tradicionalmente manuseava aeronaves norte-americanas. Mas havia uma grande desvantagem que pesava ao mencionado caça, qual seja: que os “[...] Estados Unidos tradicionalmente criam barreiras para a venda de armamentos e transferência de tecnologia” (DIAS JUNIOR; PORTO, 2010, p. 71).

Por fim, o caça Rafale F3 da Dassault (França) apresentava as seguintes vantagens: 1 - transferência de tecnologia: diferentemente do acontecia com o caça sueco, o avião francês não tinha nenhuma peça fabricada nos Estados Unidos da América, não havendo nenhuma barreira para a cessão de tecnologia para o Brasil, ao passo queos “[...] fabricantes franceses prometem transferência irrestrita de tecnologia ao Brasil caso vençam a concorrência. Além disso, segundo um dos relatórios da FAB, o Rafale F3 apresenta os melhores índices técnicos entre os concorrentes, sendo então, provavelmente, o melhor caça entre os três para o cumprimento das funções de combate" (DIAS JUNIOR; PORTO, 2010, p. 70); 2 - interesse político: o qual se perfazia por ambas as partes já que o “[...] Brasil busca, há tempos, apoios políticos que o façam entrar no Conselho de Segurança das Nações Unidas. Um parceiro como a França seria de grande valia nesta empreitada. Além disso, a França busca solidificar sua influência na América Latina e vê o Brasil como elemento essencial para este projeto" (DIAS JUNIOR; PORTO, 2010, p. 70). Porém, o avião francês apresentava algumas desvantagens, quais sejam: 1 - elevado custo global, ou seja, por unidade e de manutenção (DIAS JUNIOR; PORTO, 2010, p. 70); 2 - a França seria o único fornecedor de todos os equipamentos militares adquiridos pelo Brasil, o que seria muito temeroso, uma vez que havendo qualquer instabilidade do fornecedor, todo o aparelhamento militar estaria comprometido.

\section{EMPRESAS TRANSNACIONAIS}

O aspecto curial aqui, é que, embora a corrida pela escolha do modelo de caça, ser de interesse dos Países, foram empresas privadas, de natureza transnacional, que estavam 
ali, na disputa. Em que pese terem contratos de confidencialidade com os Estados onde possuem suas sedes, as mesmas tem um enorme papel, neste contexto.

Pensando em termos de Defesa Nacional, essas empresas possuem um papel no cenário contemporâneo globalizado, e isto, para nós é conveniente? Entender o seu papel é o trabalho deste tópico.

Muito embora as empresas transnacionais tenham começado a apresentar uma expressiva atuação somente a partir do século XX, em que "um número de organizações, inicialmente sediadas nos países desenvolvidos, que começam a expandir-se em direção aos mercados asiáticos, latino-americano e africano" (CRETELLA NETO, 2012, p. 785), ao longo da história vemos uma série de fatores que foram se somando e contribuindo para o crescimento destas empresas no cenário mundial até alcançarem o enorme poderio econômico e dinamismo que vislumbramos nos dias atuais. Assim, temos os fatores de aprimoramento tecnológico e desenvolvimento dos meios de comunicação representando um dos pilares para a expansão das transnacionais, já que facilitaram a atuação das empresas espalhadas pelos diversos Estados do globo, pois diminuíram o tempo e os custos nesta interligação das companhias. Além disso, temos o fator do “[...] protecionismo tarifário imposto pela maior parte dos países, para diminuir o volume de produtos importados e promover o desenvolvimento da indústria nacional" (CRETELLA NETO, 2012, p. 747), o que fazia com que as transnacionais objetivassem se instalar nesses países com o intuito de fornecer seus produtos ou serviços de maneira competitiva.

Assim, com o evidente aprimoramento e desenvolvimento das empresas transnacionais pelo mundo, destaca-sea importância do seu estudo, do qual, inicialmente, cumpre trazer à baila o conceito aplicável a estas companhias, o qual nas palavras de José Cretella Neto vislumbram-se como sendo:

Empresa Transnacional é a sociedade mercantil, cuja matriz é constituída segundo as leis de determinado Estado, na qual a propriedade é distinta da gestão, que exerce controle, acionário ou contratual, sobre uma ou mais organizações, todas atuando de forma concertada, sendo a finalidade de lucro perseguida mediante atividade fabril e/ou comercial em dois ou mais países, adotando estratégia de negócios centralmente elaborada e supervisionada, voltada para a otimização das oportunidades oferecidas pelos respectivos mercados internos. (CRETELLA NETO, 2006, p. 27).

Para Luiz Olavo Baptista:

Anossovera empresa transnacionaléumaentidadequenãopossuipersonalidade jurídica própria. É composta por um certo número de subsidiárias e tem uma ou mais sedes, constituídas em diversos países, de acordo com a legislação local que lhes dá personalidade jurídica e, sob certo aspecto, a nacionalidade [...] não existe a empresa transnacional [...] aproxima-se do conceito jurídico de grupo de sociedades, mas com o acréscimo de que é um grupo constituído por sociedades sedeadas em países diferentes, constituídas sob leis diversas, cada qual com certa autonomia, agindo por sua conta, mas em benefício do conjunto". (BAPTISTA, 1987, p. 17).

O autor Luiz Olavo Baptista ainda menciona em sua obra que existem dois tipos de empresas transnacionais quando se analisa a sua forma de atuação no mercado global, 
sendo que o primeiro tipo é aquele em que cada subsidiária atua de forma independente, enquanto que o segundo diz respeito as empresas que buscam integrar todas as suas operações das subsidiárias, estabelecendo um centro de comando sobre os objetivos gerais a serem alcançados com o trabalho conjunto desempenhado por cada uma das subsidiárias (BAPTISTA, 1987, p. 23).

Portanto, a empresa transnacional é aquela que a partir da organização dos fatores de produção passa a realizar suas atividades de produção e/ou prestação de serviços em 02 ou mais Estados distintos, sob a jurisdição destes Estados, concatenados para o cumprimento de metas e objetivos comuns a partir dos comandos gerais da empresa matriz, a qual detêm o controle acionário ou contratual, podendo desempenhar suas atividades através de subsidiárias que contam com maior autonomia ou aproveitando cada uma das subsidiárias para desempenhar um papel na constituição do produto final.

Contudo, para além de uma conceituação, devemos abordar algumas questões peculiares no que pertine as empresas transnacionais, sendo que a primeira delas é a relação de amor e ódio apresentada por Luiz Olavo Baptista, que consiste no fato de que os Estados necessitam dos investimentos destas companhias em seus territórios, pois as mesmas trazem riqueza, ajudam no crescimento econômico do país, trazem avanços tecnológicos, geram empregos, além de serem capazes de "de mobilizar significativos recursos para financiar campanhas políticas, pesquisas científico-tecnológicas e a própria vida econômica das comunidades onde pretendam instalar-se" (CRETELLA NETO, 2012, p. 778), mas ao mesmo tempo temem a atuação das referidas empresas, por medo de se tornarem escravizados pelas mesmas através da perda da soberania, dependência tecnológica, dominação dos mercados, influência política, além de que as transnacionais têm um planejamento econômico de atuação como se estivesse em um mercado mundial, o que resulta em uma despreocupação quanto aos interesses locais, ou seja, desinteresse quanto ao bem comum das comunidades em que constitui as suas sedes, tanto é que em muitos casos são responsáveis pela geração de dumping social, já que procuram se instalar em país que ofereçam uma mão de obra mais barata. Nesse viés, de forma complementar, José Cretella Neto também alerta pela reciprocidade do amor e ódio que as companhias transnacionais têm com os Estados, senão vejamos:

Essa falta de adequado entrelaçamento perdura até hoje, restando as desconfianças de partea parte: de um lado, os países precisam das transnacionais para investir, para recolher tributos ao Tesouro e ampliar as oportunidades de trabalho, além de exportar bens e gerar divisas, mas temem perder o atributo que reputam tão precioso, sua ratio essendi, a soberania, bem como aquilo que entendem como inegociável, o "seu" mercado nacional; de outro, as empresas transnacionais necessitam dos Estados para expandir os negócios e, ao tornar as operações globalizadas, diluir o risco de operar em um um ou em poucos países, mas mantém com os governos, não raro, relações promíscuas, pagando por benefícios concedidos, mas desconfiando dos governantes venais que as favorecem" (CRETELLA NETO, 2012, p. 786).

O que se verifica, portanto, é que diante dos temores apresentados pelos Estados, estes tendem a fazer uma regulamentação nas atividades das empresas transnacionais, com o intuito de manterem um controle sobre as mesmas, ou seja, para que não venham 
a interferir nos rumos do Estado fora dos seus objetivos estabelecidos, além de que o controle pelo Estado se faz necessário para assegurar a competitividade das empresas nacionais, as quais normalmente não conseguem concorrer em condições de igualdade perante estes gigantes internacionais, mas que ainda sim apresentam-se como de sua importância para os países, devendo portanto ser preservadas e protegidas de alguma forma.

Desta forma, resta claro o objetivo dos Estados em tentarem regulamentar as companhias transnacionais, gerando “[...] a subordinação das empresas transnacionais aos objetivos econômicos e aos valores culturais e sociais dos países nos quais operam. Por isso, através de normas de ordem pública, buscam afirmar a sua soberania estabelecendo restrições à liberdade de operar das empresas transnacionais - p. ex., impondo limites à remessa de lucros, de royalties ou fazendo exigências em matéria de transferência de tecnologia" (BAPTISTA, 1987, p. 4/5), como bem alertou Celso Lafer no prefácio do livro de Luiz Olavo Baptista.

Outra tentativa, para além do objetivo de regulamentação interna dos países sobre as transnacionais, foi a tentativa de estabelecer legislações uniformes para os blocos de integração regional, chegando-se a pensar em um órgão supranacional que pudesse fazer a fiscalização destas empresas através da aplicação de sanções pelo descumprimento da lei uniformemente constituída, contudo tal situação, conforme Luiz Olavo Baptista elucida, é uma verdadeira utopia, já que os Estados não tendem a abrir mão de sua soberania em prol de uma entidade supranacional, bem como em razão de interesses muitas vezes conflitantes entre os países (BAPTISTA, 1987, p. 49/50).

Por fim, argumentou-se ainda em uma tentativa de regulamentação das empresas transnacionais por meio do Direito Internacional Privado, suscitando a possibilidade de aplicação da legislação interna de cada país para além de suas fronteiras, já que não se chegou a instituição de uma lei internacional que pudesse normatizar as atividades das transnacionais.

Nisto, Luiz Olavo Baptista explica os insucessos dessas situações através de alguns simbolismos, senão vejamos:

\footnotetext{
Primeiro, o ideal de regulamentar as empresas transnacionais, submetendo-as a uma só legislação é quimera. Os ensaios de enquadrá-las a partir do Direito Internacional Privado, assemelham-se aos "voos" do peixe voador, de curto alcance, pela total inadequação do organismo em causa, à tentativa heroica que faz. Finalmente, esforço de regulamentar a empresa transnacional através de esquemas de cooperação regional é simbolizado pelo avestruz que, ao enterrar a cabeça, pensa esconder-se. (BAPTISTA, 1987, p. 13).
}

Ainda, temos que ressaltar que hoje em dia as empresas transnacionais são vistas como sujeitos auxiliares do Direito Internacional, sem contudo possuírem capacidade para figurarem como parte nos órgãos de solução de controvérsias em âmbito internacional, de modo que "[...] não se lhe concede o direito de defender os próprios direitos na jurisdição internacional, em status equivalente ao dos demais sujeitos do Direito Internacional" (CRETELLA NETO, 2012, p. 772/773). Muito embora se defenda que as empresas transnacionais devam ser reconhecidas como sujeitos e 
dotadas de personalidade jurídica perante o Direito Internacional Público, ainda não se tem um reconhecimento efetivo nesse sentido, permanecendo as mesmas com uma personalidade jurídica relativamente limitada.

Menciona-se por fim que as empresas transnacionais podem assumir diversas formas para se implementarem nos diversos Estados do globo levando-se em conta fatores econômicos, administrativos e jurídicos, podendo ser na condição de empresa matriz, filial, subsidiária ou associada.

O que nos retorna a questão, de embora sejam os caças, produzidos por tais empresas, elas, de fato, representam os interesses de seus Países originários, infiltrandose, adequando-se à estrutura dos demais Países. E é esse, um dos paradoxos: modernizarse à custa da tecnologia alheia, tem seu preço.

\section{CONCLUSÃO}

Os investimentos nas forças armadas dizem respeito à defesa nacional, a qual compete a União promovê-la por intermédio de políticas públicas que assegurem a efetividade no aparelhamento militar.

Nesse viés é que se desenvolveu o inicial projeto F-X e subsequente F-X2 na compra de caças supersônicos pela Força Aérea Brasileira (FAB), no intuito de que fosse feito um reaparelhamento da frota aérea, que encontrava-se defasada. Assim decorridos mais de 13 anos, o procedimento licitatória teve seu encerramento com a vitória da empresa Sueca Saab, fabricante do caça JAS 39 Gripen New Generation, sendo que além da aquisição inicial de 36 aeronaves, pactuou-se a transferência de tecnologias para o Brasil.

Portanto, a aquisição dos caças supersônicos pelo governo brasileiro, além de trazer um reaparelhamento moderno para as Forças Armadas Brasileira (FAB), garantiu um imenso avanço científico-tecnológico através da transferência de tecnologia irrestrita pela empresa vencedora do procedimento licitatório.

O papel das empresas transnacionais no cenário mundial é de uma atuação para além das fronteiras dos Estados de origem, já que visualizam em diferentes mercados a otimização de suas oportunidades, vivenciando assim uma constante relação de amor e ódio com os Estados hospedeiros, vez que estes necessitam dos investimentos trazidos pelas transnacionais, mas temem pelo tamanho do seu poderio econômico na afetação de decisões soberanas.

Assim, no que tange a perspectiva apresentada sobre o projeto F-X2, as empresas concorrentes no procedimento licitatório, já demonstravam interesses transnacionais a partir do momento em que entraram no pleito para a venda de caças supersônicos ao Brasil, mas especialmente no quesito da transferência de tecnologia, com a instalação de filiais e subsidiárias em nosso país.

Destaca-se nesse sentido que a vencedora Saab pretende construir uma fábrica em São Bernardo do Campo/SP, local onde serão produzidas todas as estruturas do caça JAS-39 Gripen NG, além de já ter adquirido 15\% do capital social da empresa brasileira Akaer, a qual ficou responsável pelo projeto de toda a fuselagem central, traseira e asas da aeronave (SILVEIRA, 2013). Além disso, conforme já mencionado anteriormente, a 
EMBRAER irá participar ativamente do desenvolvimento de sistemas, da integração, dos testes em voo, montagem final e entregas dos aviões, entre outros (EMBRAER, 2014), o que evidencia os objetivos de atuação da empresa sueca para além de suas fronteiras, caracterizando-se como verdadeira empresa transnacional.

Com a transferência de tecnologia, e criação de uma empresa com participação brasileira, minora-se, em boa parte, mas não na totalidade, o desafio de defesa aérea do território nacional. Precisamos sim, dessa tecnologia e a maneira mais eficiente, não mais barata, é a que o Brasil adotou.

\section{REFERÊNCIAS}

ALMEIDA, Carlos Wellington de. Política de defesa no Brasil: considerações do ponto de vista das políticas públicas. Campinas: Opinião Pública, v. 16, n. 1, jun. 2010. Disponível em: < http://www.scielo.br/scielo.php?script=sci arttext\&pid=So104-62762010000100009 >. Acesso em: 28 jul. 2016.

BARBOSA, Enio. Programa FX-2 de modernização de caças da FAB pode contribuir para o avanço da indústria nacional - Transferência tecnológica possibilita inovação com risco menor. Disponível em: < http://inovacao.scielo.br/pdf/cinov/v6n1/14.pdf >. Acesso em: 28 jul. 2016.

BAPTISTA, Luiz Olavo. Empresa transnacional e direito. São Paulo: Revista dos Tribunais, 1987.

BRASIL. Constituição da República Federativa do Brasil, de o5 de outubro de 1988. Disponível em: < http://www.planalto.gov.br/ccivil_03/Constituicao/Constituicao.htm >. Acesso em: 28 jul. 2016.

Decreto-lei no 5.452, de $1^{\circ}$ de maio de 1943. Disponível em: < http://www. planalto.gov.br/ccivil_o3/decreto-lei/Del5452.htm >. Acesso em: 28 jul. 2016.

Decreto no. 5.484, de 30 de junho de 2005. Disponível em: < http://www. planalto.gov.br/ccivil_03/_Ato2004-2006/2005/Decreto/D5484.htm >. Acesso em: 28 jul. 2016.

Lei no. 8.666, de 21 de junho de 1993. Disponível em: < http://www.planalto. gov.br/ccivil_03/leis/L8666cons.htm >. Acesso em: 03 ago. 2016.

CRETELLA NETO, José. Curso de direito internacional econômico. São Paulo: Saraiva, 2012.

Empresa transnacional e direito internacional. Rio de Janeiro: Forense, 2006. 
DIAS JUNIOR, Walter José Moreira; PORTO, Henrique Fernandes Alvarez Vilas. O jogo de interesses internacionais: Trajetória do Projeto F-X e influência política na decisão do Projeto F-X2. Revista de Estudos Internacionais (REI), ISSN 2236-4811, v. 1 (2), 2010.

EMBRAER. Embraer e Saab serão parceiras na gestão conjunta do Projeto F-X2 no Brasil. Publicado: 11/o7/2014. Disponível em: < http://www.embraer.com.br/pt-BR/ ImprensaEventos/Press-releases/noticias/Paginas/Embraer-Saab-serao-parceiras-nagest\% $\mathrm{C}_{3} \% \mathrm{~A}_{3}$-do-Projeto-FX2-no-Brasil.aspx >. Acesso em: o3 ago. 2016.

FORÇA AÉREA BRASILEIRA. Aeronave apresentada na Suécia é batizada como caça inteligente. Publicado em: 18/05/2016b. Disponível em: < http://www.fab.mil.br/ noticias/mostra/25819/GRIPEN\%2oNG\%20-\%20Aeronave\%2oapresentada\%2ona\%20 Su\%C3\%A9cia\%20\%C3\%A9\%2obatizada\%2ocomo\%2oca\%C3\%A7a\%2ointeligente >. Acesso em: 03 ago. 2016.

Futuro caça da Força Aérea Brasileira é apresentado na Suécia nesta quarta-feira (18). Publicado: 17/05/2016a. Disponível em: < http://www.fab.mil.br/ noticias/mostra/25781/GRIPEN\%2oNG\%20-\%2oFuturo\%2oca\%C3\%A7a\%2oda\%20 For\%C3\%A7a\%2oA\%C3\%A9rea\%2oBrasileira\%2o\% $3 \%$ A9\%2oapresentado\%2ona\%2o Su\%C3\%A9cia\%2onesta\%2oquarta-feira\%2o(18 >. Acesso em: 03 ago. 2016.

FOLHA DE S. PAULO. FAB prefere caça sueco a francês. São Paulo: 05/o1/2010. Disponível em: < http://www1.folha.uol.com.br/poder/2010/o1/674679-fab-prefere-caca-sueco-afrances.shtml >. Acesso em: 03 ago. 2016.

FARCIC, Pedro Luís. Ministério Público Federal arquiva inquérito sobre a compra de caças. Brasília: 10/o9/2015. Disponível em: < http://www.fab.mil.br/noticias/ mostra/22925/NOTA\%2oOFICIAL\%2o-\%2oMinist\%C3\%A9rio\%2oP\%C3\%BAblico\%2o Federal\%2oarquiva\%2oinqu\%C3\%A9rito\%2osobre\%2oa\%2ocompra\%2ode\%2o ca\% $3 \%$ A7as >. Acesso em: 03 ago. 2016.

JUSTEN FILHO, Marçal. Comentários à lei de licitações e contratos administrativos: lei 8.666/1993. 16. ed., rev., atual., e ampl. São Paulo: Revista dos Tribunais, 2014.

SILVEIRA, Virgínia. Brasil escolhe caça sueco Gripen NG; vitória beneficia Embraer e Akaer. Publicado: 18/12/2013. Disponível em: < http://www.valor.com.br/ brasil/337589o/brasil-escolhe-caca-sueco-gripen-ng-vitoria-beneficia-embraer-e-akaer >. Acesso em: 03 ago. 2016.

Embraer é favorável à compra de caças suecos. São José dos Campos: 28/o9/2009. Disponível em: < http://www.valor.com.br/arquivo/785439/embraer-efavoravel-compra-de-cacas-suecos >. Acesso em: 03 ago. 2016. 
UBIRATAN, Edmundo. Como o Gripen NG venceu o Programa F-X2. Brasília: 29/o1/2014. Disponível em: < http://aeromagazine.uol.com.br/artigo/como-o-gripenng-venceu-o-programa-f-x2_1331.html >. Acesso em: 03 ago. 2016. 